\title{
Glycotoxins Relationship with Body Mass Index (BMI)
}

Received: 19-Apr-2020 Accepted: 12-Jul-2020 Published: 16-Dec-2020

\section{Aseel Abd Ali Yousif ${ }^{1,}$, Mufeda Ali Jwad ${ }^{1}$, Nadia Al-Hilli}

\section{${ }^{1}$ High Institute of Infertility Diagnosis and Assisted Reproductive Technologies, Al Nahrain University, Baghdad, Iraq. * aseelalfil@ gmail.com \\ ${ }^{2}$ Department of Obstetrics \& Gynecology, College of Medicine, University of Babylon, Babylon, Iraq.}

Glycotoxins termed as advanced glycation endproducts (AGEs) are made endogenously and exogenously. Maillard reaction is a chemical non-enzymatic process, between sugars and a free amino acid group of nucleic acids, proteins, and lipids which happens exogenously when handled with high temperature for a prolonged period and in a dry environment, resulting in glycotoxins (AGEs) formations. This reaction is responsible for the taste, color, and smell of food. Glycotoxins derived from food are absorbed in the intestine and store in cells and tissues. Also, glycotoxins are derived exogenously from smoking. While endogenous glycotoxins are generated by normal body physiology. Obesity and insulin resistance may induce glycotoxins (AGEs) accumulation. The objective of this study was to evaluate the relationship between glycotoxins (AGEs) and obesity. 66 infertile females who were undergoing intracytoplasmic sperm injection ICSI. These females were classified into three groups according to their body mass index. On the day of ova pick up the collect serum and follicular fluid for subsequent measurement of glycotoxins (AGEs) by ELISA kits. there was a significant difference in the concentration of glycotoxins in follicular fluid and serum between the three ICSI groups of patients. As well as there was a significant difference in the concentration of glycotoxins (AGEs) in follicular fluid and serum in the same ICSI groups of patients. there is a significant positive relation between glycotoxins (AGEs) and increase BMI.

Keywords: Glycotoxins; AGES; ICSI; BMI. 


\section{Introduction}

Glycation is a spontaneous non-enzymatic process of reducing sugars and free amino groups of nucleic acid, proteins, and lipids, that forms Schiff's base. Then the Schiff's base is converted into the more stable product 'Amadori product'. This product then undergoes many reactions after a period of weeks to form advanced glycation end products (AGEs) which are called Glycotoxins (Mohammadi, M. ${ }^{[1]}$ ). It is constituting a group of complexes compound of over twenty members (Monnier and Sell ${ }^{[2]}$; Ramasamy, et al. ${ }^{[3]}$; Merhi, Z. ${ }^{[4]}$ ). N-carboxymethyl-lysine and Pentosidine are regarded as wellknown glycotoxins and have been used as signs of AGEs (glycotoxins) accumulation in different tissues (Merhi, et al. ${ }^{[5]}$; Diamanti-Kandarakis, et al. $\left.{ }^{[6]}\right)$. AGEs levels in Serum and body tissue depend on endogenous and exogenous sources. Exogenous sources result from diet and smoking. While endogenous AGEs are generated by normal body physiology, but when an excessive number of AGEs accumulate in the body leads to a pathological change occur such as oxidative stress and Inflammation over numerous ways at the tissue and cellular level.

1. AGEs (glycotoxins) bind with cellular surfaces or cross-link with body proteins leading to hardness of the protein matrix and modifying their function (Ayatollahi, et al. ${ }^{[7]}$ ).

2. They bind with a receptor for advanced glycation end products (AGEs-RAGE) resulting in disturbance of cellular signaling pathways (Ahmad, et al. ${ }^{[8]}$ ).

3. Peroxidation of lipid led to troubled endothelial function, stimulating oxidative stress and inflammation (Rojas, et al. ${ }^{[9]}$; Rehman, et al. ${ }^{[10]}$ ). There are two types of glycotoxins (AGEs) receptor, Receptor-dependent AGEs (RAGE) which are an immunoglobulin superfamily that binds with various family's ligands (Merhi, et al. $\left.{ }^{[11]}\right)$. The interaction of AGEs with the receptordependent AGEs starts the stimulation of 
downstream signaling paths leading to the startup of several inflammatory cytokines and more up-regulation of the receptor leads to a positive feedback loop (Kalea, et al. $\left.{ }^{[12]}\right)$. The second type of AGEs receptor called soluble AGEs receptor (sRAGE), which are extracellular receptors and found in circulating blood (DiamantiKandarakis, et al. [13]; DiamantiKandarakis, et al. ${ }^{[14]}$ ). Soluble RAGE (sRAGE) can counterbalance the outcome mediated by RAGE-ligand binding and may neutralize RAGE-mediated pathogenesis by acting as a decoy. Therefore, it is theorized that when the concentration of s-RAGE is increased, it could bind more ligands (AGEs) which might prevent the activation of downstream signaling thus may reduce the inflammation and oxidative stress caused by glycotoxins. In comparison to normal AGEs receptor (RAGE), soluble AGEs receptor (sRAGE) is regarded as a 'good' receptor (Diamanti-Kandarakis, et al. $\left.{ }^{[15]}\right)$. The key factors that influence the rate of glycotoxins formation is a nutrient composition that is more in protein, then in fat and less in carbohydrate. Moreover, depending on temperature and length of heat application, humidity, $\mathrm{pH}$, and amount of trace metals contained (Goldberg, et al. ${ }^{[16]}$; Uribarri, et al. ${ }^{[17]}$ ). Therefore, glycotoxins (AGEs) contained in food can significantly be modified by different cooking methods without necessarily changing the nutrient composition. For example, the same amount of chicken has been used, but handling it with different cooking techniques for the same period, will make very different glycotoxins content (the number of AGEs in steaks and roast chickens is much higher than in other foods) (Lin, et al. ${ }^{[18]}$ ). Metabolic syndrome affected about $20-30 \%$ of the adult population worldwide, which is characterized by central obesity and insulin resistance. This disease is multifactorial, resulting from complex genetic and environmental influences such as physical inactivity, smoking, and a diet rich in sugars and saturated fatty acids. 
Obesity and insulin resistance may induce glycotoxins (AGEs) accumulation (Merhi, Z. $\left.{ }^{[19]}\right)$.

\section{Materials and Methods}

This prospective comparative study included sixty-six infertile females who were undergoing intracytoplasmic sperm injection ICSI at the High Institute of Infertility Diagnosis and Assisted Reproductive Technologies, Al Nahrain University, Baghdad, Iraq, From July 2019 to May 2020. These females were divided into three groups according to their body mass index

\section{BMI = Weight $(\mathrm{kg}) /$ Height $\left(\mathrm{m}^{2}\right)$}

- Normal BMI $=18.5-24.9 \mathrm{~kg} / \mathrm{m}^{2}$

- Overweight $\mathrm{BMI}=25-29.9 \mathrm{~kg} / \mathrm{m}^{2}$

- Obese BMI $\geq 30 \mathrm{~kg} / \mathrm{m}^{2}$

Inclusion criteria consisted of Females age 19 - 43 years with ovarian dysfunction, tubal factors, idiopathic factors, male factors infertility except those with nonobstructive azoospermia, and both male and female factors. While exclusion criteria include: Females with BMI $<18.5$ $\mathrm{kg} / \mathrm{m}^{2}$, Male with non-obstructive azoospermia, females with endocrine disorders like (liver, kidney, and heart disease) and blood vessel diseases (Yao, et al. $\left.{ }^{[20]}\right)$. On the $2^{\text {nd }}$ day of the menstrual cycle all patients were subjected to full history, physical and gynecological examination, transvaginal ultrasound examination to assess the number of antral follicles, baseline hormonal assay, husband's seminal fluid analysis all steps were explained to the couple and confirmed their agreement (Al-Obaidi, et al. $\left.{ }^{[21]}\right)$.

\subsection{Ovarian stimulation and cycle monitoring}

Patients underwent IVF/ICSI using two types of Controlled ovarian Hyperstimulation $(\mathrm{COH})$ protocols, which are either the flexible antagonist protocol or Short, and early follicular antagonist protocol (sandwich protocol). Antagonist protocol was used in 62 infertile females in which gonadotropin ( $\mathrm{rFSH} \alpha$, Gonal-F®; Merck Serono, Geneva, Switzerland) subcutaneous injection administered on 
the $2^{\text {nd }}$ or $3^{\text {rd }}$ day of the menstrual cycle at different dosages according to the patient's age and the previous response of ovulation induction. Then pituitary down-regulation with daily subcutaneous injection of GnRH antagonist (Cetrorelix acetate injection $0.25 \mathrm{mg}$ : CetrotideR, Merk, Switzerland) when follicular size reached $14 \mathrm{~mm}$ in diameter then triggering with an injection of 5000- 10,000 IU of rhCG were applied 34-36 hours before oocytes retrieval (Paulson, RJ. ${ }^{[22]}$ ). The sandwich protocol was used in selected cases (four cases) which are either poor responder or old age females. GnRH antagonist Cetrotide was given $0.25 \mathrm{mg} /$ day from cycle day two for three days in order to elongate the follicular phase and increase recruitment. When the leading follicle reaches 12-14 $\mathrm{mm}$ take Cetrotide again until triggering day (Bruyneel, et al. ${ }^{[23]}$ ). The $\mathrm{COH}$ was monitored by both serum $\mathrm{E}_{2}$ levels and transvaginal ultrasound (Costello, et al. ${ }^{[24]}$ ). Transvaginal ultrasound-guided oocyte retrieval was performed, and then ICSI was done 40-42 $\mathrm{h}$ after triggering. Oocytes were considered to be fertilized when two pronuclei were observed at 17-18 hr. following insemination or ICSI (Venturella, et al. ${ }^{[25]}$ ).

\subsection{Serum and Follicular Fluid collection}

A blood sample was obtained on the day of oocyte retrieval, left in a gel tube, and then centrifuged for 10 minutes at $5000 \mathrm{rpm}$ to separate the serum. Follicular fluid was obtained from the first retrieved follicle to avoid contamination of blood and media used during aspiration, put in a plane tube, and then centrifuged for 10 minutes at $3000 \mathrm{rpm}$. The supernatant of follicular fluid and the serum was collected and stored at $-40^{\circ} \mathrm{C}$ until analysis.

\subsection{Measurements of glycotoxins (AGEs)}

Enzyme-linked immunosorbent assay (ELISA) kits (Cusabio Biotech Co. Ltd, Wilmington, DE, USA) was used to measure the level of glycotoxins (AGEs) in follicular fluid and serum. The within- 
and between assay coefficients of variation were $(\mathrm{CV} \%<8 \%)$ and $(\mathrm{CV} \%<10 \%)$ respectively.

\section{Statistical Analysis}

Statistical analysis was performed by using statistical package of science (SPSS); version 25.0 and Microsoft excel worksheet 2010. Numeric variables were expressed as Mean \pm standard deviation while nominal variables were expressed as number and percentage by using the chisquare test. The significance of the differences between values was considered statistically significant at the level of $\mathrm{p}<0.05$, which was done by using a one-way ANOVA test.

\section{Results}

The demographic characteristics (age and duration of infertility) of infertile females enrolled in the present study are shown in Table 1, which are expressed as either Mean \pm Standard Deviation (SD) or percentage. The statistical analysis showed no significant difference $(\mathrm{P}>0.05)$ between the three ICSI groups in age and duration of infertility. The gonadotropin dose that is the total number of ampoules used in stimulation days and the duration of stimulation (which is the number of days from starting of gonadotropin until triggering day) were recorded as Mean \pm Standard Deviation (SD) in Table 1. Statistically, there was no significant difference $(p>0.05)$ in the gonadotropin dose and duration of stimulation between the three ICSI groups of patients. Baseline hormonal status of ICSI groups of patients with respect to BMI was shown in Table 2. There was no significant difference in mean serum hormonal level between normal, overweight, and obese ICSI groups of patients $(p>0.05)$. Concerning the allocation of glycotoxins (AGEs) concentration in follicular fluid and serum, there was a significant difference between the three ICSI groups of patients p-value was (0.000) as shown in Table 3. It showed that the highest concentration of AGEs (in follicular fluid and serum) was found in obese ICSI groups of patients 
Table (1): Comparison of clinical characteristics of all participants undergoing IVF/ICSI

\begin{tabular}{|c|c|c|c|c|}
\hline Groups & $\begin{array}{c}\text { Normal } \\
(\mathbf{n = 2 2})\end{array}$ & $\begin{array}{c}\text { Overweight } \\
(\mathbf{n}=22)\end{array}$ & $\begin{array}{c}\text { Obese } \\
(\boldsymbol{n}=22)\end{array}$ & P-value \\
\hline $\begin{array}{c}\text { Age }(\boldsymbol{y r}) \\
\text { (Mean } \pm \text { SD) })\end{array}$ & $27.6 \pm 5.8$ & $29.6 \pm 5.6$ & $31.4 \pm 5.9$ & $0.1 \mathrm{NS}$ \\
\hline $\begin{array}{c}\text { Duration of } \\
\text { infertility }(\boldsymbol{y r}) \\
\text { (Mean } \pm \text { SD) }\end{array}$ & $7.9 \pm 3.9$ & $5.6 \pm 3.2$ & $6 \pm 3.7$ & $0.1 \mathrm{NS}$ \\
\hline $\begin{array}{c}\text { Days of stimulation } \\
\text { (Mean } \pm \text { SD) }\end{array}$ & $10.3 \pm 1.7$ & $10.2 \pm 1.5$ & $10.7 \pm 1.1$ & $0.5 \mathrm{NS}$ \\
\hline $\begin{array}{c}\text { Gonadotropin } \\
\text { ampoules }\end{array}$ & $20.7 \pm 10.4$ & $20.6 \pm 11.9$ & $25.5 \pm 14.1$ & $0.3 \mathrm{NS}$ \\
\hline
\end{tabular}

SD: Standard deviation; n: number; NS: not significant at $\mathrm{p}>0.05$; One-way ANOVA test

Table (2): Comparison of hormonal levels

\begin{tabular}{|c|c|c|c|c|}
\hline Hormone & $\begin{array}{c}\text { Normal } \\
\text { Mean } \pm \text { SD }\end{array}$ & $\begin{array}{c}\text { Overweight } \\
\text { Mean } \pm \text { SD }\end{array}$ & $\begin{array}{c}\text { Obese } \\
\text { Mean } \pm \text { SD }\end{array}$ & P-value \\
\hline D2 FSH (IU/l) & $6.9 \pm 2.6$ & $6.94 \pm 3.5$ & $8.21 \pm 3.1$ & $0.46 \mathrm{NS}$ \\
\hline D2 LH (IU/l) & $5.42 \pm 2.5$ & $4.12 \pm 1.6$ & $4.4 \pm 2.1$ & $0.254 \mathrm{NS}$ \\
\hline D2 TSH (IU/l) & $1.49 \pm 0.63$ & $1.62 \pm 0.92$ & $1.46 \pm 0.71$ & $0.504 \mathrm{NS}$ \\
\hline D2 PRL (ng/ml) & $18.7 \pm 7.3$ & $20.3 \pm 14.7$ & $21.12 \pm 9.7$ & $0.82 \mathrm{NS}$ \\
\hline D2 E2 (pg/ml) & $34.19 \pm 15.2$ & $42.2 \pm 15.9$ & $33.9 \pm 16.3$ & $0.13 \mathrm{NS}$ \\
\hline $\begin{array}{c}\text { Triggering day } \boldsymbol{E}_{2} \\
(\boldsymbol{p g} / \mathbf{m l})\end{array}$ & $1531.84 \pm 667.2$ & $1932.95 \pm 703.66$ & $1150.19 \pm 150.15$ & $0.64 \mathrm{NS}$ \\
\hline
\end{tabular}

SD: standard deviation; FSH: follicle-stimulating hormone; E2: Estradiol; TSH: thyroid-stimulating hormone; PRL: prolactin. One-way ANOVA; S: significant at $\mathrm{p} \leq 0.05$; NS: not significant at $\mathrm{p}>0.05$. 
Table (3): Advanced Glycation Endproducts concentration in follicular fluid and serum

\begin{tabular}{|c|c|c|c|c|}
\hline $\begin{array}{c}\text { The variable } \\
(\mathbf{p g} / \mathrm{ml})\end{array}$ & $\begin{array}{c}\text { Normal } \\
(\text { Mean } \pm \text { SD })\end{array}$ & $\begin{array}{c}\text { Over weight } \\
(\text { Mean } \pm \text { SD })\end{array}$ & $\begin{array}{c}\text { Obese } \\
(\text { Mean } \pm \text { SD })\end{array}$ & P-value \\
\hline AGEs-F & $177.73 \pm 49.6$ & $264.49 \pm 66.4$ & $374.13 \pm 31.1$ & $0.000 \mathrm{HS}$ \\
\hline AGEs-S & $147.96 \pm 26$ & $242.38 \pm 59$ & $398.94 \pm 39$ & $0.000 \mathrm{HS}$ \\
\hline $\boldsymbol{P}$-value & $0.04 \mathrm{~S}$ & $0.04 \mathrm{~S}$ & $0.04 \mathrm{~S}$ & \\
\hline
\end{tabular}

AGEs-F: Advanced Glycation Endproducts concentration in follicular fluid; AGEs-S: Advanced Glycation Endproducts concentration in serum; SD: standard deviation. S: significant at $\mathrm{p} \leq 0.05$;

NS: not significant at $\mathrm{p}>0.05$; HS: highly significant at $\mathrm{p}=0.000$.

$(374.13 \pm 31.1 \quad$ and $\quad 398.94 \pm 39)$

respectively. While the lowest concentration was found in normal ICSI groups of patients $(177.73 \pm 49.6$ and $147.96 \pm 26)$ in follicular fluid and serum respectively. As well as there was a significant difference in the concentration of AGEs in follicular fluid and serum in the same ICSI groups of patients $\mathrm{P}=0.04$.

\section{Discussion}

Infertility defines according to the Oxford English Dictionary as "inability to give birth or procreate" (Deyhoul, et al. ${ }^{[26]}$ ). The problems enclosing infertility are several and complicated, which is combined with the advanced maternal age at which more couples are trying to achieve pregnancy. Throughout the past two decades, the typical conception age has increased from 29.4 to 32.8 years of age (Oduola, et al. $\left.{ }^{[27]}\right)$ and, predictably, up to one in six couples are seeking fertility treatment (de Oliveira, et al. ${ }^{[28]}$ ). Probably due to bad quality oocyte, ovarian disorder, and reproductive system complaints such as fallopian tube diseases, endometriosis, and leiomyoma (Vitale, et al. ${ }^{[29]}$ ). In the current study, the mean \pm SD for age (years) of all ICSI 
groups of patients is $29.4 \pm 5.9$. It was found that there was no significant difference in the mean age and the duration of infertility between the three ICSI groups of patients (normal, overweight, and obese). This finding agrees with another study which, stated that (age and infertility duration) are important factors to eliminate any variable that may affect the results of the measured parameter which may affect the ICSI outcome (Lambalk, et al. ${ }^{[30]}$ ). The mean duration of ovarian stimulation and the dose of gonadotropin were calculated in all females who participated in the study. These variables were essential to evaluate the response to ovarian stimulation protocol. The dose of gonadotropin and duration of stimulation are considered as markers for ovarian response to stimulation (Khalaf, et al. ${ }^{[31]}$ ). Previously it was defined ovarian reserve as the ability of the ovaries to respond to gonadotropin with sufficient follicular development. A significant number of women were found to respond poorly or not at all to this treatment, such patients have been referred to as low responders and having diminished ovarian reserve (Wintner, et al. ${ }^{[32]}$ ). In the present study, a comparison was done between the duration of stimulation and the total gonadotrophin dose between the three ICSI groups of patients. The results showed no significant differences between the three ICSI groups of patients. This finding agrees with that of previous systematic reviews which reported that no significant adverse effects of elevated BMI on IVF outcomes (Schliep, et al. ${ }^{[33]}$ ). While disagreeing with other studies, which stated that an elevated BMI associated with higher gonadotropin dose requirement, collection few oocytes, cancellation rates high, pregnancy and live birth rates reduced, in addition to increased miscarriage rates (Caillon, et al. ${ }^{[34]}$; Sarais, et al. ${ }^{[35]}$ ). Basal hormonal level illustrated in Table 2, there was no significant difference between the three ICSI groups of patients because all disturbed hormones are usually corrected 
before starting ovarian stimulation protocols. Advanced glycation endproducts are destructive complexes that are created through the nonenzymatic change of proteins, lipids, and nucleic acid by sugars. Excess levels of these compounds in the tissues and circulation may involve many pathogenic pathways (Kheirouri, et al. ${ }^{[36]}$ ). AGEs have pathogenic importance in chronic diseases (Davis, et al. ${ }^{[37]}$ ) due to involvement in the elevation of oxidative stress, inflammation, and apoptosis (Peters, et al. ${ }^{[38]}$ ). In the present study, the statistical analysis showed that there was a significant difference in the concentration of AGEs in follicular fluid and serum between the three ICSI groups of patients $(\mathrm{P}=0.000)$. Also, in the same group, there was a significant difference in the concentration of AGEs in follicular fluid and serum $(\mathrm{P}=0.04)$. These results agree with another study that demonstrates that obese AGEs are significantly higher than non-obese (Antoniotti, et al. ${ }^{[39]}$ ). While disagreeing with other studies that stated that There was no correlation between obesity and circulating AGEs (Garay-Sevilla, et al. $\left.{ }^{[40]}\right)$. The effect of AGEs is classified as receptor-dependent via binding to the AGE receptor (RAGE) or receptorindependent (such as cross-links with extracellular matrix) (Haddad, et al. ${ }^{[41]}$ ). An extracellular form of AGEs receptor, called soluble receptor for AGE (sRAGE), circulates in the blood (Piperi, et al. ${ }^{[42]}$ ). The Soluble AGEs receptor is generally considered a good receptor because it acts as a decoy by binding the circulating toxic AGEs, thus the adverse intracellular AGEs actions in all organs including the ovaries are inhibiting (Fujii and Nakayama $\left.{ }^{[43]}\right)$. These results support the present study, which conducted that there was a significant difference in AGEs concentration in follicular fluid and serum, and higher concentration was found in the follicular fluid than in serum in normal and overweight ICSI groups of patients due to increase (sRAGE) in blood circulation, which binds to toxic AGEs 
and decreased its circulating level. While obese ICSI groups of patients had higher AGEs concentration in serum than in follicular fluid. This agrees with another study, which stated that plasma sRAGE inversely correlates with factors of metabolic syndrome, for example, obesity. Obese women have significantly lower serum sRAGE concentrations when compared with normal-weight females (Li, et al. $\left.{ }^{[44]}\right)$.

\section{Conclusions}

Obesity is associated with an increase in the concentration of advanced Glycation End products (AGEs) in follicular fluid and serum.

\section{Acknowledgment}

We would like to acknowledge the High Institution of Infertility Diagnosis and Assisted Reproductive Technologies, Al Nahrain University, Baghdad, Iraq.

\section{Funding}

This work received no funding.

\section{Author Contribution}

Yousif, AAA performed the study, examined and reviewed results, and manuscript writing with the help and supervision of Jwad MA, and Al-Hilli, N.

\section{Conflict of Interest}

The authors declare no conflict of interest.

\section{Ethical Clearance}

The study was approved by the Ethical Approval Committee.

\section{References}

[1] Mohammadi M. Oxidative stress and polycystic ovary syndrome: A brief review. Int J Prev Med. 2019;10::68. [Online Article Link]

[2] Monnier VM, Sell DR. Prevention and repair of protein damage by the Maillard reaction in vivo. Rejuvenation Res. 2006;9(2):264-73. [Online Article Link]

[3] Ramasamy R, Yan SF, Schmidt AM. The diverse ligand repertoire of the receptor for advanced glycation endproducts and pathways to the complications of diabetes. Vascul Pharmacol. 2012;57(5-6):160-7. [Online Article Link] 
[4] Merhi Z. Vitamin D attenuates the effect of advanced glycation end products on anti-Mullerian hormone signaling. Mol Cell Endocrinol. 2019 Jan 5;479:87-92. [Online Article Link]

[5] Merhi Z, Doswell A, Krebs K, Cipolla M. Vitamin D alters genes involved in follicular development and steroidogenesis in human cumulus granulosa cells. J Clin Endocrinol Metab. 2014;99(6):E1137-45. [Online Article Link]

[6]Diamanti-Kandarakis E, Chatzigeorgiou A, Papageorgiou E, Koundouras D, Koutsilieris M. Advanced glycation end-products and insulin signaling in granulosa cells. Exp Biol Med. 2016;241(13):1438-45. [Online Article Link]

[7] Ayatollahi SAM, Kobarfard F, Asgarpanah J, Choudhary MI. Antiglycation activity of Otostegia persica (Burm.) Boiss. African J Biotechnol. 2010;9(24):3645-8. [Online Article Link]

[8] Ahmad S, Khan H, Siddiqui Z, Khan MY, Rehman S, Shahab U, et al. AGEs, RAGEs and s-RAGE; friend or foe for cancer. Semin Cancer Biol. 2018;49:44-55. [Online Article Link]

[9]Rojas A, Figueroa H, Morales E. Fueling inflammation at tumor microenvironment: the role of multiligand/RAGE axis. Carcinogenesis. 2010;31(3):334-41. [Online Article Link]
[10] Rehman R, Abidi SH, Alam F. Metformin, Oxidative Stress, and Infertility: A Way Forward. Front Physiol. 2018;9:1722:1-4. [Online Article Link]

[11] Merhi Z, Kandaraki EA, DiamantiKandarakis E. Implications and Future Perspectives of AGEs in PCOS Pathophysiology. Trends Endocrinol Metab. 2019;30(3):150-62. [Online Article Link]

[12] Kalea AZ, Schmidt AM, Hudson BI. RAGE: a novel biological and genetic marker for vascular disease. Clin Sci. 2009;116(8):621-37. [Online Article Link]

[13] Diamanti-Kandarakis E, Piperi C, Kalofoutis A, Creatsas G. Increased levels of serum advanced glycation end-products in women with polycystic ovary syndrome. Clin Endocrinol (Oxf). 2005;62(1):37-43. [Online Article Link]

[14] Diamanti-Kandarakis E, Katsikis I, Piperi C, Alexandraki K, Panidis D. Effect of long-term orlistat treatment on serum levels of advanced glycation end-products in women with polycystic ovary syndrome. Clin Endocrinol (Oxf). 2007;66(1):103-9. [Online Article Link]

[15] Diamanti-Kandarakis E, Alexandraki K, Piperi C, Aessopos A, Paterakis T, Katsikis I, et al. Effect of metformin administration on plasma advanced glycation end product levels 
in women with polycystic ovary syndrome. Metabolism. 2007;56(1):129-34. [Online Article Link]

[16] Goldberg T, Cai W, Peppa M, Dardaine V, Baliga BS, Uribarri J, et al. Advanced glycoxidation end products in commonly consumed foods. $\mathrm{J}$ Am Diet Assoc. 2004;104(8):1287-91. [Online Article Link]

[17] Uribarri J, Woodruff S, Goodman S, Cai W, Chen X, Pyzik R, et al. Advanced glycation end products in foods and a practical guide to their reduction in the diet. J Am Diet Assoc. 2010;110(6):911-6.e12. [Online Article Link]

[18] Lin P, Chang C, Wu K, Shih C, Chiang $\mathrm{W}$, Chen $\mathrm{H}$, et al. Dietary Glycotoxins , Advanced Glycation End Products, Inhibit Cell Proliferation and Progesterone Secretion in Ovarian Granulosa Cells and Mimic PCOSLike Symptoms. Biomolecules 2019;9, 327:1-17. [Online Article Link]

[19] Merhi Z. Advanced glycation end products and their relevance in female reproduction. Hum Reprod. 2014;29(1):135-45. [Online Article Link]

[20] Yao Q, Liang Y, Shao Y, Bian W, $\mathrm{Fu} \mathrm{H}, \mathrm{Xu} \mathrm{J}$, et al. Advanced glycation end product concentrations in follicular fluid of women undergoing IVF/ICSI with a GnRH agonist protocol. Reprod Biomed Online. 2018;36(1):20-5. [Online Article Link]

[21] Al-Obaidi MT, Mahdi HB, Alwasiti E. The impact of age and BMI on oocyte maturation and embryo development. Biomed Res. 2018;29(9):1920-4. [Online Article Link]

[22] Paulson RJ. At last, an orally active gonadotropin-releasing hormone antagonist. Fertil Steril. 2019;111(1):30-1. [Online Article Link]

[23] Bruyneel A, Papas R, Delbaere A. Ovulation Induction With Gonadotropins. In: Encyclopedia of Endocrine Diseases (Second Edition). Reference Module in Biomedical Sciences. 2019; 2:570-580. [Online Article Link]

[24] Costello MF, Misso ML, Balen A, Boyle J, Devoto L, Garad RM, et al. Evidence summaries and recommendations from the international evidence-based guideline for the assessment and management of polycystic ovary syndrome: assessment and treatment of infertility. OUP accepted manuscript. Hum Reprod Open. 2019; 2019(1): hoy02. [Online Article Link]

[25] Venturella R, Vaiarelli A, Cimadomo D, Pedri S, Lico D, Mazzilli R, et al. State of the art and emerging drug therapies for female 
infertility. Gynecol Endocrinol. 2019 Oct;35(10):835-841. [Online Article Link]

[26] Deyhoul N, Mohamaddoost T, Hosseini M. Infertility-related risk factors: A systematic review. Int $\mathbf{J}$ Women's Heal Reprod Sci. 2017;5(1):24-9. [Online Article Link]

[27] Oduola OO, Ryan GA, Umana E, Conway U, Purandare N. Ovulation induction: comparing success rates between anovulatory and ovulatory cycles using different treatment protocols. Gynecol Endocrinol. 2019;35(11):978-980. [Online Article Link]

[28] de Oliveira AA, Vieira CP, de Azambuja P, Penna MLF. Comparative study of regulations of assisted reproduction between England, Italy, Norway and Ireland. Hum Reprod Arch. 2017;32(3):e000917. [Online Article Link]

[29] Vitale SG, Rossetti P, Corrado F, Rapisarda AMC, La Vignera S, Condorelli RA, et al. How to Achieve High-Quality Oocytes? The Key Role of Myo-Inositol and Melatonin. Int J Endocrinol. 2016;2016; 4987436:1-9.

[Online Article Link]

[30] Lambalk CB, Banga FR, Huirne JA, Toftager M, Pinborg A, Homburg R, et al. GnRH antagonist versus long agonist protocols in IVF: a systematic review and meta-analysis accounting for patient type. Hum Reprod Update. 2017;23(5):560-79. [Online Article Link]

[31] Khalaf M, Mittre H, Levallet J, Hanoux V, Denoual C, Herlicoviez M, et al. GnRH agonist and GnRH antagonist protocols in ovarian stimulation: differential regulation pathway of aromatase expression in human granulosa cells. Reprod Biomed Online. 2010;21(1):56-65. [Online Article Link]

[32] Wintner EM, Hershko-Klement A, Tzadikevitch K, Ghetler Y, Gonen O, Wintner O, et al. Does the transfer of a poor quality embryo together with a good quality embryo affect the In Vitro Fertilization (IVF) outcome? J Ovarian Res. 2017;10(2):1-5. [Online Article Link]

[33] Schliep KC, Mumford SL, Ahrens KA, Hotaling JM, Carrell DT, Link M, et al. Effect of male and female body mass index on pregnancy and live birth success after in vitro fertilization. Fertil Steril. 2015;103(2):388-95. [Online Article Link]

[34] Caillon H, Fréour T, Bach-Ngohou $\mathrm{K}$, Colombel A, Denis MG, Barrière $\mathrm{P}$, et al. Effects of female increased body mass index on in vitro fertilization cycles outcome. Obes Res Clin Pract. 2015;9(4):382-8. [Online Article Link]

[35] Sarais V, Pagliardini L, Rebonato G, Papaleo E, Candiani M, Viganò P. 
A comprehensive analysis of body mass index effect on in vitro fertilization outcomes. Nutrients. 2016;8(3):109. [Online Article Link]

[36] Kheirouri S, Alizadeh M, Maleki V. Zinc against advanced glycation end products. Clin Exp Pharmacol Physiol. 2018;45(6):491-8. [Online Article Link]

[37] Davis KE, Prasad C, Vijayagopal P, Juma S, Imrhan V. Advanced glycation end products, inflammation, and chronic metabolic diseases: Links in a chain? Crit Rev Food Sci Nutr. 2016;56(6):989-98. [Online Article Link]

[38] Peters AE, Mihalas BP, Bromfield EG, Roman SD, Nixon B, Sutherland JM. Autophagy in Female Fertility: A Role in Oxidative Stress and Aging. Antioxidants Redox Signal. 2020 Mar 10;32(8):550-568. [Online Article Link]

[39] Antoniotti GS, Coughlan M, Salamonsen LA, Evans J. Obesity associated advanced glycation end products within the human uterine cavity adversely impact endometrial function and embryo implantation competence. 2018;33(4):654-65.

[Online Article Link]

[40] Garay-Sevilla ME, Torres-Graciano S, Villegas-Rodríguez ME, RiveraCisneros AE, Wrobel K, Uribarri J. Advanced glycation end products and their receptors did not show any association with body mass parameters in metabolically healthy adolescents. Acta Paediatr Int $J$ Paediatr. 2018;107(12):2146-51. [ [Online Article Link]

[41] Haddad M, Knani I, Bouzidi H, Berriche O, Hammami M, Kerkeni M. Plasma levels of pentosidine, carboxymethyl-lysine, soluble receptor for advanced glycation end products, and metabolic syndrome: The metformin effect. Dis Markers. 2016;2016,6248264. [Online Article Link]

[42] Piperi C, Adamopoulos C, Dalagiorgou G, Diamanti-Kandarakis E, Papavassiliou AG. Crosstalk between advanced glycation and endoplasmic reticulum stress: emerging therapeutic targeting for metabolic diseases. J Clin Endocrinol Metab. 2012;97(7):2231-42. [Online Article Link]

[43] Fujii EY, Nakayama M. The measurements of RAGE, VEGF, and AGEs in the plasma and follicular fluid of reproductive women: the influence of aging. Fertil Steril. 2010;94(2):694700. [Online Article Link]

[44] Li Y, Chen J, Sun P, Li J, Liang X. Intrafollicular Soluble RAGE Benefits Embryo Development and Predicts Clinical Pregnancy in Infertile Patients of Advanced Maternal Age Undergoing In Vitro Fertilization. 


\section{7;37(2):243-7. [Online Article} Link]

\section{Authors Biographies}

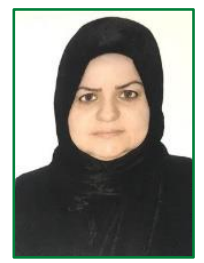

\section{Dr. Aseel Abd Ali Yousif}

Received the MBCHB from the College

of Medicine, $\mathrm{Al}$ Mustansiriya

University in 2002. Worked in Maysan city as a rotator and resident doctor from 2002-2006, and she is currently in

Maysan city. She was the manager of maternal and child healthcare in the Maysan Health Department from 2011-2017. She received the M.Sc. degree in 2020 and she is currently a Ph.D. student at the High Institute for infertility diagnosis and assisted reproductive technologies, Al Nahrain University.

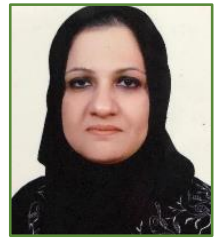

\section{Dr. Mufeda Ali Jwad}

She received her MBChB. From the College of Medicine at the University of Baghdad in 1996. Her M.Sc. in Applied Embryology and her Ph.D. in Infertility and Clinical Reproduction were from the High Institute of Infertility Diagnosis and Assisted Reproductive Technologies, Al Nahrain University in 2007 and 2018 respectively. She worked as a rotator in the Baghdad health department from 1996-1999. She worked in Gyn. \& Obs. in Alsamawa general hospital and Babylon hospital from 2000-2003. She worked at the Babylon University, College of Medicine, anatomy and embryology department from 2003-2004. She has been working as a specialist physician and a consultant clinic at the High Institute of Infertility Diagnosis and Assisted Reproductive Technologies, Al Nahrain University from 2008-2015. Currently, she is an assistant professor and specialist in infertility and clinical reproduction. She is the head of the clinical reproductive physiology department from 2019 till now. She has more than 25 published articles in national and international journals.

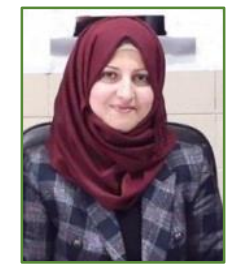

\section{Dr. Nadia Mudher}

Sulaiman Al-Hilli

She was born in Babylon, Iraq in 1976.

She received the M.B.Ch.B. from the College of Medicine, the University of
Babylon in 1999, the Diploma in Obs. \& Gyne in 2005, Iraqi Board in Obs. \& Gyne (FIBMS) in 2006, the Part I MRCOG in 2006, and the Certificate of minimal access surgery from the Iraqi Ministry of Health in 2017. Currently, she is an Assistant Professor and the Head of the department in Obs. \& Gyne department, College of Medicine, University of Babylon. She is also a lecturer and supervisor of Ph.D. students in the High Institute of Infertility and Assisted Reproductive Technologies since 2016. She is a member of the medical education committee at the University of Babylon, College of Medicine, and a member of the scientific committee of Obs. \& Gyne. department at the University of Babylon, College of Medicine. She participated in more than, 25 Symposiums, 3 International Symposiums, 18 National Conferences, 15 International Conferences, 16 Workshops, and 9 Training Courses. She published more than 21 articles both local and international. She has more than 200 diagnostic \& operative hysteroscopy operations \& More than 200 diagnostic and operative laparoscopies performed for infertility patients.

\section{How to cite:}

Yousif AAA; Jwad MA; Al-Hilli N. Glycotoxins Relationship with Body Mass Index (BMI); Iraqi Journal of Embryos and Infertility Researches (IJEIR), (2020); 10(1): 51-66.

Doi: http://doi.org/10.28969/IJEIR.v10.i1.r4

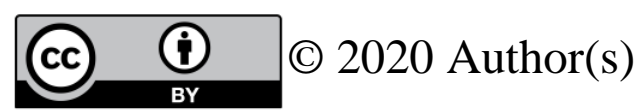

This article is licensed under a Creative Commons Attribution 4.0 International License, which permits use, sharing, adaptation, distribution and reproduction in any medium or format, as long as $\mathrm{y}^{*}$ ou give appropriate credit to the original author(s) and the source, provide a link to the Creative Commons license, and indicate if changes were made. http://creativecommons.org/licenses/by/4.0/. 